\title{
Estimating the depth and shape of subglacial Lake Vostok's water cavity from aerogravity data
}

\author{
Michael Studinger, ${ }^{1}$ Robin E. Bell, ${ }^{1}$ and Anahita A. Tikku ${ }^{2,3}$ \\ Received 24 February 2004; revised 27 April 2004; accepted 17 May 2004; published 19 June 2004.
}

[1] We use aerogravity data to estimate the water depth of subglacial Lake Vostok in East Antarctica. The inversion produces the first bathymetry map covering the entire lake. Lake Vostok consists of two sub-basins separated by a ridge with very shallow water depths. The deeper southern subbasin is approximately double the spatial area of the smaller northern sub-basin. The close correlation between the pattern of basal melting and freezing and the bathymetric structure has important ramifications for the water circulation and the sediment deposition. We estimate the lake volume to be $5400 \pm 1600 \mathrm{~km}^{3}$. INDEX TERMS: 1219 Geodesy and Gravity: Local gravity anomalies and crustal structure; 1827 Hydrology: Glaciology (1863); 3010 Marine Geology and Geophysics: Gravity; 3260 Mathematical Geophysics: Inverse theory; 9310 Information Related to Geographic Region: Antarctica. Citation: Studinger, M., R. E. Bell, and A. A. Tikku (2004), Estimating the depth and shape of subglacial Lake Vostok's water cavity from aerogravity data, Geophys. Res. Lett., 31, L12401, doi:10.1029/2004GL019801.

\section{Introduction}

[2] The discovery of subglacial lakes in Antarctica and their potential for harboring life has prompted a widespread debate on the conditions necessary to support life in such extreme environments [Kapitsa et al., 1996; Karl et al., 1999; Priscu et al., 1999; Siegert et al., 2001, and references therein]. Lake Vostok, to date the largest subglacial lake known on Earth, lies beneath 3700 to $4300 \mathrm{~m}$ of ice in the interior of East Antarctica. The water circulation within subglacial Lake Vostok provides a viable mechanism for transporting mass and energy through the lake, enhancing the potential for the support of biota. The circulation pattern depends on the geometry of the lake bathymetry [Mayer et al., 2003; Williams, 2001].

[3] To date, the lake bathymetry is known from sparse seismic soundings [Masolov et al., 1999, 2001]. To determine the depth and shape of the water cavity over the entire lake we use aerogravity data acquired along a regional grid [Studinger et al., 2003a]. The free-air gravity anomaly field reflects density variations related to both major geological and topographic structures including changes in the lake water depth. The influence of the regional subglacial topography and the geometry of the overlying ice sheet is

\footnotetext{
${ }^{1}$ Lamont-Doherty Earth Observatory of Columbia University, Palisades, New York, USA.

${ }^{2}$ Ocean Research Institute, The University of Tokyo, Tokyo, Japan

${ }^{3}$ Now at Department of Earth \& Environmental Sciences, Rensselaer Polytechnic Institute, Troy, New York, USA.
}

Copyright 2004 by the American Geophysical Union. 0094-8276/04/2004GL019801\$05.00 well constrained from ice-penetrating radar measurements and can be removed from the observed gravity anomaly (Figure 1). The unknown parameter that dominates the remaining gravity anomaly is the lake water depth. The lake water depth can be inverted from the aerogravity data. The aim of this paper is to estimate the depth and shape of Lake Vostok's water cavity and to evaluate the ramifications for the water circulation in light of the pattern of melting and freezing.

\section{Aerogeophysical Data}

[4] We use aerogeophysical data consisting of laser altimeter, ice-penetrating radar, and gravity measurements collected on a $157.5 \times 330 \mathrm{~km}$ grid by the US National Science Foundation's Support Office for Aerogeophysical Research (SOAR) (Figure 1). East-west oriented flight lines were spaced $7.5 \mathrm{~km}$ apart and the north-south oriented tie lines are 11.25 and $22.5 \mathrm{~km}$ apart [Richter et al., 2001; Studinger et al., 2003a, 2003b]. Flight elevation was $3960 \mathrm{~m}$ above sea-level. Acquisition parameters and data reduction are described by J. W. Holt et al. (manuscript in preparation, 2004). The spatial resolution of the aerogravity data is limited by the removal of highamplitude noise by low-pass filtering [Bell et al., 1999]. The filter is a cosine taper that begins its roll-off at $0 \mathrm{~Hz}$ and reaches infinite attenuation at $0.006 \mathrm{~Hz}$ [Childers et al., 1999]. This corresponds to a cut-off wavelength of $11.6 \mathrm{~km}$ at an average speed of $70 \mathrm{~m} / \mathrm{s}$ of the survey aircraft. Crossover errors at flight line intersections have been minimized by removing a linear trend from the network. The standard deviation of the adjusted crossover error is $2.7 \mathrm{mGal}$.

\section{Inversion of Gravity Data}

[5] The gravity effect $\Delta g(x, y)$ of a topographic relief $h(x, y)$ with a lateral varying density contrast $\Delta \rho(x, y)$ across an interface can be expressed as a Taylor series of Fourier transformations [Parker, 1973]:

$$
F[\Delta g(x, y)]=-2 \pi \gamma e^{-\bar{k} z_{0}} \sum_{n=1}^{n=\infty} \frac{\bar{k}^{n-1}}{n !} F\left[\Delta \rho(x, y) h^{n}(x, y)\right]
$$

with $x$ and $y$ being the spatial coordinates, $\gamma$ being the gravitational constant, $z_{0}$ being the mean depth of the interface, and $F$ denoting the Fourier transformation. $k_{\mathrm{x}}$ and $k_{\mathrm{y}}$ are the wavenumbers in the frequency domain along the $x$ and $y$ coordinates in the spatial domain. The radial wavenumber is $\bar{k}=\sqrt{k_{x}+k_{y}}$.

[6] Before inverting the observed free-air gravity field we removed the gravity effect of the ice sheet. The surface and 

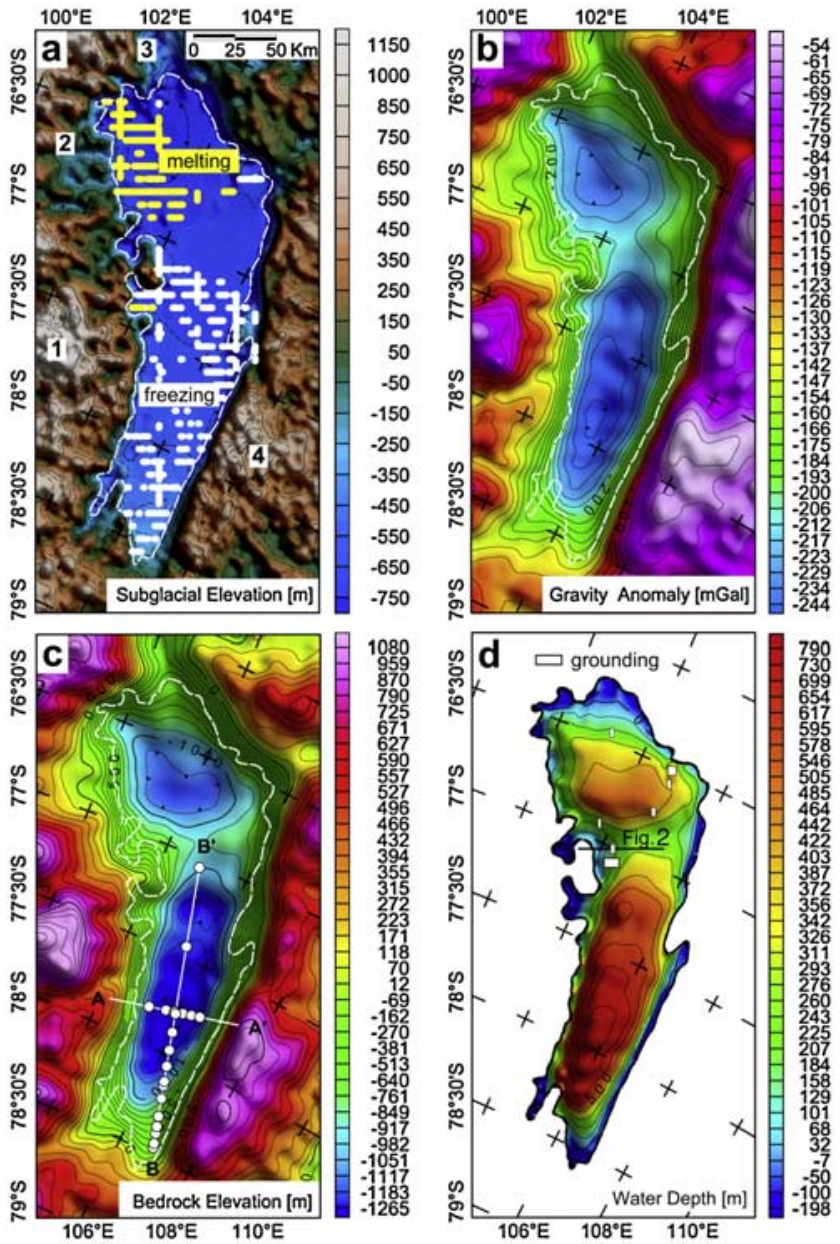

Figure 1. a) Bedrock and lake surface elevation in $m$ above sea level referenced to the WGS 84 ellipsoid. White dashed line marks shore line of Lake Vostok. Dashed contours mark $100 \mathrm{~m}$ interval and solid contour lines mark $500 \mathrm{~m}$ intervals. Numbers refer to discussion in text. White lines mark locations where we observe the accreted ice reflector in the radar data and yellow lines indicate locations with fuzzy lake reflectors coinciding with the regions of melting (A. A. Tikku et al., manuscript in preparation, 2004). b) Gravity anomaly used for the inversion process. The gravity effect of the ice sheet has been removed from the free-air anomaly. Contour interval is $10 \mathrm{mGal}$. c) Bedrock elevation in $\mathrm{m}$ estimated from gravity inversion. Contour interval is $100 \mathrm{~m}$. White circles mark depth estimates from seismic soundings shown in Figure 3. d) Bathymetry estimated from gravity inversion and lake surface elevation. Contour interval is $100 \mathrm{~m}$. The positive water depths reflect inconsistencies within the uncertainty of the aerogravity data. White boxes indicate regions with grounded ice observed from radar.

bottom of the ice sheet are well constrained from laser altimeter and ice-penetrating radar measurements, respectively [Studinger et al., 2003a]. The gravitational effect of the ice sheet at the flight elevation can be calculated from equation (1) using $\rho_{i c e}=900 \mathrm{~kg} / \mathrm{m}^{3}$. After removing the gravity effect of the ice sheet from the observed free-air anomaly field the resulting gravity field reflects the free-air anomaly of the bedrock topography and a water-filled lake (Figure 1b).

[7] We have estimated the contributions of the individual terms of the Taylor series of the density contrast across the subglacial topography/ice sheet interface constrained from ice-penetrating radar measurements. The density contrast $\Delta \rho$ across the ice sheet/bedrock interface is $1770 \mathrm{~kg} / \mathrm{m}^{3}$ assuming $\Delta \rho=\rho_{\text {bedrock }}-\rho_{\text {ice }}$ for $\rho_{\text {bedrock }}=2670 \mathrm{~kg} / \mathrm{m}^{3}$. Both, the wavelength and maximum amplitude of the contributions from second and higher order terms are below the detection threshold determined by the cut-off wavelength of our filtering scheme.

[8] The smaller density contrast between the bedrock/water interface $\Delta \rho=1670 \mathrm{~kg} / \mathrm{m}^{3}$ for $\rho_{\text {water }}=1000 \mathrm{~kg} / \mathrm{m}^{3}$ results in smaller amplitude gravity anomalies. The bedrock/water interface is farther away from the flight elevation again reducing anomaly amplitudes. The anticipated gravity contributions of the higher order terms of the bedrock/water interface are estimated to be below the cut-off wavelength and detection threshold of our aerogravity data. Subsequently, equation (1) can be reduced to only the first term of the Parker expansion:

$$
F[\Delta g(x, y)]=-2 \pi \gamma e^{-\bar{k} z_{0}} F[\Delta \rho(x, y) h(x, y)]
$$

Equation (2) can be simply rearranged to estimate the product of the unknown topographic relief $h(x, y)$ and a given density contrast $\Delta \rho(x, y)$ :

$$
F[\Delta \rho(x, y) h(x, y)]=-\frac{F[\Delta g(x, y)] e^{\overline{k_{z}}}}{2 \pi \gamma}
$$

The expression on the right-hand side contains a downward continuation which will accentuate short-wavelength signals including noise. Downward continuation of potential field data close to the source level is inherently unstable. The aerogravity data was low-pass filtered with a cosine taper in the frequency domain which has its cut-off wavelength at $11.6 \mathrm{~km}$. Downward continuation of the data from the flight elevation $(3960 \mathrm{~m})$ to the mean elevation of the interface will affect mainly wavelengths below the cut-off wavelength of the gravity filter and thus only affect noise contained in the data and not the gravity signal of the topographic surface. For this reason we can neglect the downward continuation $\left(e^{k z_{0}} \approx 1\right)$. After a back transformation into the spatial domain and rearrangement equation (3) turns into the equivalent of the simple Bouguer slab formula:

$$
h(x, y)=\frac{\Delta g(x, y)}{2 \pi \gamma \Delta \rho(x, y)}
$$

[9] The resulting inversion still contains long-wavelength signals associated with the Moho structure and the major geologic boundary beneath Lake Vostok [Studinger et al., 2003a, 2003b]. We have chosen to use the regional topography to remove the long-wavelength signals. We use the misfit between the regional bedrock topography inverted from gravity and the bedrock topography from radar data to isolate the unknown long-wavelength effect of deeper crustal sources. We calculated a trend of the order of two, 
fitted through the misfit outside the lake, and removed this trend from the inverted gravity anomaly.

\section{Bathymetry of Lake Vostok}

[10] The estimated bathymetry of the gravity inversion demonstrates that Lake Vostok consists of two sub-basins (Figure 1). The southern sub-basin is much deeper and approximately twice the spatial area of the smaller northern sub-basin. The two sub-basins are separated by a ridge with very shallow $(\sim 200 \mathrm{~m})$ water depths (Figure 1d). The separation of Lake Vostok in two distinct sub-basins may have important ramifications for the water circulation within the lake. To estimate the reliability of our gravity inversion we compare the depth estimates from the gravity inversion with independent estimates from ice-penetrating radar data and seismic soundings over the lake.

\subsection{Comparison With Ice-Penetrating Radar Data}

[11] The subglacial topography outside the lake has been systematically mapped from ice-penetrating radar data [Studinger et al., 2003a] (Figure 1a). The major topographic features observed in the radar data are reproduced in the gravity inversion. These include a pronounced high in subglacial topography west of the lake (No 1), a wide embayment northwest of the lake (No 2), a narrow embayment at the northern tip of the lake (No 3), the steep slope along the entire eastern coast line of Lake Vostok, and a pronounced high in the southeastern corner (No 4). The general agreement between our depth estimates and the independent estimates from ice-penetrating radar supports the idea that the bathymetry of Lake Vostok can be reliably estimated from our aerogravity data. The maximum difference between a low-pass filtered bedrock topography from radar and the gravity inversion ranges between $-460 \mathrm{~m}$ and $680 \mathrm{~m}$ with a standard deviation of $175 \mathrm{~m}$.

[12] Over the lake, we observe several reflectors on the ice-penetrating radar where the ice sheet is grounded (Figure 2). The grounded ice near $104^{\circ} \mathrm{E}$ and $77^{\circ} \mathrm{S}$ coincides with shallow $(<200 \mathrm{~m})$ water depths (Figure 1d). At the northern end of the lake (near $105^{\circ} \mathrm{E}$ and $76^{\circ} 30^{\prime} \mathrm{S}$ ) grounding coincides with shallow water depths (tens of meters) interpreted from radar [Gorman and Siegert, 1999].

\subsection{Comparison With Seismic Depth Soundings}

[13] The water depth of Lake Vostok has been estimated from seismic soundings along several profiles [Masolov et al., 1999, 2001] (Figures 1c and 3). The depth estimates from gravity inversion compare well with the seismic depth estimates. The maximum difference between the seismic and the gravimetric estimates is between $-510 \mathrm{~m}$ and $300 \mathrm{~m}$

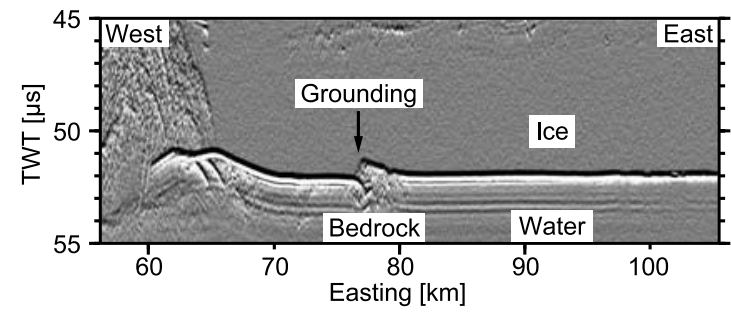

Figure 2. Ice-penetrating radar profile showing grounded ice. For location see Figure 1d. TWT is two-way travel time.
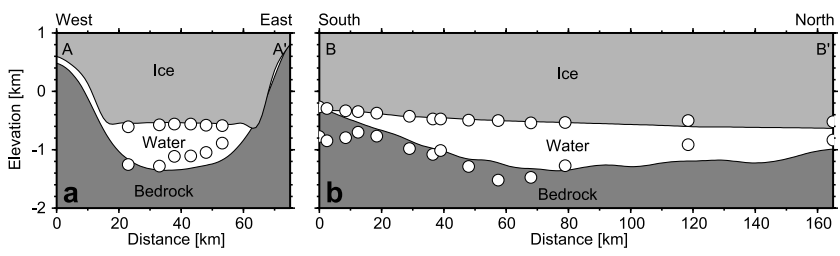

Figure 3. Comparison between depth estimates from seismic soundings [Masolov et al., 1999, 2001] indicated by open circles and inversion of aerogravity data (gray areas). For location of profiles see Figure 1c.

with a standard deviation of $250 \mathrm{~m}$. The north-south profile shows small-scale discrepancies near kilometer 10 and 60 which are below the lateral resolution of our aerogravity data. The $2.7 \mathrm{mGal}$ uncertainty in our gravity data corresponds to a $\sim 250 \mathrm{~m}$ uncertainty in depth estimates for the density contrast used. Our depth estimates agree with the seismic depth estimates within the confidence limit.

\subsection{Potential Errors and Uncertainties}

[14] While our depth estimates over the lake coincide very well with the seismic estimates there are several inconsistencies with the subglacial topography and the bottom of the ice sheet along the edge of the lake (Figure 3a). These inconsistencies include gaps between the bedrock and the ice sheet as well as overlaps. Likely reasons for these inconsistencies are lateral variations in density structure which have not been addressed in the inversion process. Furthermore, the exact density of the bedrock beneath Lake Vostok is not known. We have evaluated a range of densities, simulating low-density sediments and high- density crystalline bedrock scenarios and we have selected a bedrock density of $2670 \mathrm{~kg} / \mathrm{m}^{3}$, which reduces the discrepancy between the seismic and gravimetric estimates to $\pm 250 \mathrm{~m}$.

[15] The ridge between the two basins could be caused by lateral density changes rather than water depth variations. The $20 \mathrm{mGal}$ and $60-\mathrm{km}$-wide gravity anomaly over the ridge would require a high density body $\left(2900 \mathrm{~kg} / \mathrm{m}^{3}\right)$ extending $3 \mathrm{~km}$ beneath the lake bottom. Because the observed gravity anomaly is truncated on the eastern and western shore the hypothetic scenario of a high-density body is unlikely within the tectonic framework suggested by Studinger et al. [2003b]. Thus, we believe a change in water depth likely causes the high in the observed gravity anomaly.

\section{Implications and Conclusions}

[16] Our bathymetry map is the first complete water depth estimate of Lake Vostok. Using the new bathymetry we estimate a volume of $5400 \pm 1600 \mathrm{~km}^{3}$ for the lake. Endmembers for the residence time of the lake water can be estimated from the present-day ice velocity of $2.0 \pm 0.01 \mathrm{~m} / \mathrm{yr}$ (R. Dietrich, personal communication, 2003) at Vostok, a paleo-velocity of $1.0 \mathrm{~m} / \mathrm{yr}$ (R. E. Bell et al., manuscript in preparation, 2004), and the volume of accreted ice transported out of the lake [Bell et al., 2002]. We estimate a residence time between 55 and $110 \mathrm{kyr}$, which is in agreement with the 70-80 kyr estimated from thermodynamic constraints [Petit et al., 2003]. 
[17] Inversion of aerogravity data shows that Lake Vostok consists of two sub-basins separated by a ridge with very shallow $(\sim 200 \mathrm{~m})$ water depths. The southern sub-basin is much deeper and approximately double the spatial area of the smaller northern sub-basin. The distribution of melting and freezing at the base of the ice sheet appears to be intimately linked to the two basin structure. The regions with basal melting and freezing have been estimated from thickness changes between internal layers along ice flow (R. E. Bell et al., manuscript in preparation, 2004). The same pattern is visible in characteristic signatures in the ice-penetrating radar data (Figure 1a). The thin layer of accreted ice at the base of the ice sheet is imaged as weak reflector in the radar data [Bell et al., 2002; A. A. Tikku et al., manuscript in preparation, 2004]. Regions of melting correlate with a fuzziness of the ice-water interface in the radar data. Over the northern basin, basal melting is dominant while over the southern basin, basal freezing characterizes the lake/ice interaction. The intimate link between the regions of melting and freezing and the bathymetric structure of the lake has important ramifications for the water circulation. If the lake water is fresh, basal meltwater in the northern basin would sink to the bottom [Siegert et al., 2001] and water exchange between the two basins will be limited. The two separate basins may have different chemical and maybe biological compositions. Furthermore, sediments released by basal meting are likely to accumulate in the northern basin while preglacial sediments are more likely to be found in the southern, deeper basin. The sampling strategy for the future recovery of sediments from the lake bottom depends on the type of sediments targeted.

[18] Acknowledgments. We thank the NSF's SOAR facility located at the University of Texas, Austin for acquisition and reduction of the aerogeophysical data. The camp crew at East Camp and the Kenn Borek flight crews provided excellent support. M. Siegert and J. R. Petit are thanked for their constructive comments. Garry Karner is thanked for discussion. Funding was provided by NSF grants OPP-9978236 and OPP-0088047. LDEO contribution 6618.

\section{References}

Bell, R. E., V. A. Childers, R. A. Arko et al. (1999), Airborne gravity and precise positioning for geologic applications, J. Geophys. Res., 104(B7), $15,281-15,292$.
Bell, R. E., M. Studinger, A. Tikku et al. (2002), Origin and fate of Lake Vostok water frozen to the base of the East Antarctic ice sheet, Nature, 417, 307-310.

Childers, V. A., R. E. Bell, and J. M. Brozena (1999), Airborne gravimetry: An investigation of filtering, Geophysics, 64(1), 61-69.

Gorman, M. R., and M. J. Siegert (1999), Penetration of Antarctic subglacial lakes by VHF electromagnetic pulses: Information on the depth and electrical conductivity of basal water bodies, J. Geophys. Res., 104(B12), 29,311-29,320.

Kapitsa, A. P., J. K. Ridley, G. D. Robin et al. (1996), A large deep freshwater lake beneath the ice of central East Antarctica, Nature, 381(6584), $684-686$.

Karl, D. M., D. F. Bird, K. Bjorkman et al. (1999), Microorganisms in the accreted ice of Lake Vostok, Antarctica, Science, 286(5447), 2144-2147.

Masolov, V. N., G. A. Kudryavtsev, A. N. Sheremetiev et al. (1999), Earth Science Studies in the Lake Vostok region: Existing data and proposals for future research, in Subglacial Lake Exploration-Workshop Report and Recommendations, Addendum, report, pp. 1-18, Cambridge Univ., U. K.

Masolov, V. N., V. V. Lukin, A. N. Sheremetiev, and S. V. Popov (2001), Geophysical investigations of the subglacial Lake Vostok in eastern Antarctica, Dokl. Earth Sci., 379(6), 734-738.

Mayer, C., K. Grosfeld, and M. J. Siegert (2003), Salinity impact on water flow and lake ice in Lake Vostok, Antarctica, Geophys. Res. Lett., 30(14), 1767, doi:10.1029/2003GL017380.

Parker, R. L. (1973), Rapid calculation of potential anomalies, Geophys. J. R. Astron. Soc., 31(4), 447-455.

Petit, J. R., M. Blot, and S. Bulat (2003), Lac Vostok: A la decouverte d'un environnement sous glaciaire et de son contenu biologique, in Environnement de la Terre primitive, edited by M. Gargaud and J. P. Parisot, pp. 273-316, Presses Univ. aires de Bordeaux, France.

Priscu, J. C., et al. (1999), Geomicrobiology of subglacial ice above Lake Vostok, Antarctica, Science, 286(5447), 2141-2144.

Richter, T. G., J. W. Holt, and D. D. Blankenship (2001), Airborne gravimetry over the Antarctic ice sheet, paper presented at the International Symposium on Kinematic Systems in Geodesy, Geomatics and Navigation, Banff, Canada.

Siegert, M. J., J. C. Ellis-Evans, and M. Tranter et al. (2001), Physical, chemical and biological processes in Lake Vostok and other Antarctic subglacial lakes, Nature, 414(6864), 603-609.

Studinger, M., et al. (2003a), Ice cover, landscape setting, and geological framework of Lake Vostok, East Antarctica, Earth Planet. Sci. Lett., 205(3-4), 195-210.

Studinger, M., G. D. Karner, R. E. Bell et al. (2003b), Geophysical models for the tectonic framework of the Lake Vostok region, East Antarctica, Earth Planet. Sci. Lett., 216(4), 663-677.

Williams, M. J. M. (2001), Application of a three-dimensional numerical model to Lake Vostok: An Antarctic subglacial lake, Geophys. Res. Lett., $28(3), 531-534$.

R. E. Bell and M. Studinger, Lamont-Doherty Earth Observatory of Columbia University, P.O. Box 1000, 61 Route 9W, Palisades, NY 109648000, USA. (mstuding@1deo.columbia.edu)

A. A. Tikku, Department of Earth \& Environmental Sciences, Rensselaer Polytechnic Institute, 110 8th Street, Troy, NY 12180, USA. 